\title{
ACESSIBILIDADE FÍSICA NA UNIVERSIDADE FEDERAL DO PARÁ SOB O OLHAR DE ESTUDANTES COM DEFICIÊNCIA
}

\section{PHYSICAL ACCESSIBILITY AT THE FEDERAL UNIVERSITY OF PARÁ THROUGH THE EYES OF DISABLED STUDENTS}

\section{ACCESIBILIDAD FÍSICA EN LA UNIVERSIDADE FEDERAL DO PARÁ BAJO LA MIRADA DE ESTUDIANTES CON DEFICIENCIA}

\author{
Carolline Septimio \\ Doutoranda em Educação pela Universidade do Estado de Santa Catarina - (UDESC). \\ Florianópolis- SC, Brasil. \\ carolpedagoga@yahoo.com.br
}

Genylton Odilon Rêgo da Rocha PhD em História da Educação pelo Institut National de Pédagogique - (INRP) da França. Professor Doutor da Universidade Federal do Pará (UFPA). Belém- PA, Brasil. genylton@gmail.com

Geovana Mendonça Lunardi Mendes Professora Doutora da Universidade do Estado de Santa Catarina. PhD em Currículo e Novas Tecnologias pela Universidad de San Andres em Buenos Aires e em Ashland University em Ohio. Florianópolis- SC, Brasil. geolunardi@gmail.com

RESUMO: O artigo ora apresentado é derivado de um recorte da dissertação de mestrado desenvolvida na Universidade Federal do Pará (UFPA). Nosso objetivo foi investigar a acessibilidade física no campus de Belém, a partir do olhar de Estudantes com deficiência. A pesquisa qualitativa foi realizada por meio de entrevistas aos Acadêmicos com diferentes tipos de deficiência e cursando graduações distintas, a fim de observar a diversidade de percepções no uso do espaço, em uma abordagem teórica ancorada em Goffman(1988), Pinto e Buffa (2009) e Diniz (2012). Como resultados destacamos que, para os Discentes, a acessibilidade física não é um conceito fixo e universal, mas construído na relação sujeito-ambiente e que as atuais obras de acesso ao espaço físico da UFPA têm sinalizado avanços para a vida acadêmica e precisam ser expandidas. Para os Estudantes, faz-se necessário o fomento a pesquisas que abordem a questão da acessibilidade física na universidade pois o campus é considerado pelos Acadêmicos como o melhor espaço de socialização de conhecimentos, ainda que existam barreiras de acesso à sua estrutura física.

PALAVRAS-CHAVE: Acessibilidade física. Estudantes com deficiência. Universidade Federal do Pará.

ABSTRACT: This article is derived from a part of the master's thesis developed at the Federal University of Pará (UFPA). Our goal was to investigate the physical accessibility on campus in Belém, through the eyes of disabled Students. The qualitative research was conducted by interviews with Students with different types of disabilities who were attending different degrees programs, in order to observe the diversity of perceptions about the use of the space, in a theoretical approach anchored on Goffman (1988), Pinto and Buffa (2009) and Diniz (2012). As a result we noticed that for Students, physical accessibility is not a steady and universal concept, but a concept built in the subject-environment relationship and that the current improvements of access to UFPA's physical space have indicated progress to the academic life but still need to be expanded. For Students, it is necessary to promote research about physical accessibility at the university because the campus is considered by scholars as the best knowledge socialization space, although there are access barriers to its physical structure.

KEYWORDS: Physical accessibility. Disabled students. Federal University of Pará. 
RESUMEN: Este artículo es derivado del recorte de la disertación de maestria desarollada en la Universidade Federal do Pará (UFPA). Nuestro objetivo fue investigar la accesibilidad física en el campus de Belém desde la mirada de los Estudiantes con deficiencia. El estudio cualitativo fue realizado a través de entrevistas a los Académicos com diferentes tipos de deficiencia y cursando distintos grados, con el propósito de observar la diversidad de percepción en el uso del espacio, en un abordaje teorica fundamentado en Goffman (1988), Pinto e Buffa (2009) e Diniz (2012). Como resultados hemos destacado que, para los Alumnos, la accesibilidad física no es un concepto fijo y universal, pero sí construido en la relación sujeto-ambiente y que las atuales obras de acceso al espacio físico de UFPA han señalado avances para la vida académica y necesitan expandirse. Para los Estudiantes, es necesario el fomento a investigaciones que aborden la questión de la accesibilidad física en la universidad, pues el campus es considerado, por los Académicos, el mejor espacio de socialización de conocimientos, aunque existan barreras de acceso a su estructura física.

PALABRAS CLAVE: Accesibilidad física. Estudiantes con deficiencia. Universidade Federal do Pará. 


\section{1| INTRODUÇÃO}

Ao abordar o processo de construção das universidades brasileiras, Pinto e Buffa (2009) destacam que havia uma intenção explícita de recrutar os melhores estudantes do país, a partir de estruturas físicas grandiosas e aparelhamento da elite dirigente. Planejar, projetar e construir uma universidade significava uma oportunidade singular de projetar o ministério e, sobretudo, o governo. A universidade, na sua definição e nos aspectos arquitetônicos e urbanísticos, não poderia deixar de ser a imagem desses anseios (PINTO; BUFFA, 2009, p. 51).

Dos anos de 1930 para os dias atuais, a expansão do ensino superior trouxe consigo marcas, tanto da escassez de recursos e aumento de vagas nos cursos, quanto a inclusão de estudantes dantes nunca vistos, ou pelo menos, não percebidos nas universidades. São negros, índios, pessoas com deficiência e outras minorias que se fazem presentes nas instituições de ensino superior. ${ }^{1}$

Dessa forma, a Universidade Federal do Pará (UFPA) também conta com um universo de Estudantes $^{2}$ com deficiência. Entendemos que essa participação não pode passar despercebida na universidade, porque demanda novas concepções de ensino e também de espaço. A partir do arcabouço teórico firmado em Goffman (1988), Pinto e Buffa (2009) e Diniz (2012), entre outros pesquisadores, levantamos como questão principal: quais as percepções dos Acadêmicos com deficiência da UFPA acerca da acessibilidade física no campus de Belém?

Com base nas respostas a esta questão, no âmbito deste artigo, apresentamos os principais resultados advindos desta investigação. Para tanto, organizamos o texto em três eixos. No primeiro são traçados os caminhos metodológicos para desenvolvimento da investigação: escolha dos entrevistados, de instrumento de coleta de dados, entre outros aspectos norteadores. No segundo são apresentadas as discussões e análises das entrevistas realizadas junto aos Estudantes com deficiência. No terceiro expusemos algumas reflexões finais trazidas pelo debate da acessibilidade física no contexto da inclusão.

Esperamos que tais escolhas possibilitem ao leitor a compreensão da perspectiva dos Estudantes ouvidos na pesquisa e suas questões sobre a Universidade.

\section{2 | CAMINHOS METODOLÓGICOS DA PESQUISA}

Entendemos que a presença de Pessoas com deficiência na UFPA motivou essa pesquisa da mesma forma que consagrou a necessidade de escutá-las, de compreender seus olhares acerca da acessibilidade física existente na universidade.

Para a seleção dos sujeitos participantes da pesquisa, fizemos um levantamento junto ao Centro de Registros e Indicadores Acadêmicos (CIAC) da UFPA dos discentes com deficiência que estudaram na UFPA nos últimos 20 anos. Assim, tivemos um total de 269 Pessoas. Destas, 146 tiveram ingresso a partir do ano de 2010.

Decidimos entrevistar apenas estudantes que ainda estivessem frequentando a Universidade e com data de ingresso a partir do ano em que as obras de acessibilidade tinham sido iniciadas no

\footnotetext{
${ }^{1}$ Diversos foram os documentos legais que oportunizaram o acesso e permanência de minorias ao Ensino Superior. Para exemplificar, o Decreto $n^{\circ}$ 3.956/01 que promulga a Convenção interamericana para eliminação da discriminação contra pessoas portadoras de deficiência e a Lei n 10.098/00, conhecida como Lei da Acessibilidade.

${ }^{2}$ Sempre que nos referirmos ao sujeito, utilizamos a letra inicial em maiúsculo "Estudante/ Discente/ Pessoa/ Acadêmico" acrescido da expressão "com deficiência". Fazemos isso para destacar a importância da Pessoa em detrimento da deficiência.
} 
campus, a saber, $2009^{3}$. Dessa forma, escolhemos 5 acadêmicos com diferentes tipos de comprometimento físico e cursando graduações distintas. São eles:

QUADRO 1 - Pessoas com deficiência entrevistadas na UFPA- campus Belém

\begin{tabular}{|c|c|c|c|c|c|c|}
\hline PESSOA & SEXO & IDADE & CURSO & INGRESSO & SEMESTRE & DEFICIÊNCIA \\
\hline A & Feminino & 29 & Arquitetura & 2012 & $4^{\circ}$ & $\begin{array}{c}\text { Física - distrofia } \\
\text { dos membros }\end{array}$ \\
\hline$B$ & Feminino & 25 & Odontologia & 2012 & $2^{\circ}$ & $\begin{array}{c}\text { Física - Perda } \\
\text { de } 90 \% \text { do } \\
\text { movimentos de } \\
\text { rotação e } \\
\text { elevação do } \\
\text { braço esquerdo }\end{array}$ \\
\hline$C$ & Feminino & 20 & Medicina & 2013 & $2^{\circ}$ & $\begin{array}{c}\text { Física - } \\
\text { Tetraparesia }\end{array}$ \\
\hline$D$ & Masculino & 21 & $\begin{array}{l}\text { Ciências } \\
\text { Contábeis }\end{array}$ & 2012 & $5^{\circ}$ & Auditiva \\
\hline$E$ & Masculino & 21 & $\begin{array}{c}\text { Engenharia da } \\
\text { Computação }\end{array}$ & 2010 & $7^{\circ}$ & Auditiva \\
\hline
\end{tabular}

Fonte: Elaborada pelos autores. Dados retirados do Centro de Registro e Indicadores Acadêmicos (CIAC).

Para cada entrevistado foram marcadas escutas em dia e horário apropriado. No intuito de manter o anonimato, designamos letras do alfabeto para cada participante, substituindo seus nomes. Foi realizada uma entrevista para cada Estudante, em local e horário reservado individualmente, totalizando 5 dias de entrevistas as quais ocorreram entre os meses de dezembro de 2013 a janeiro de 2014. Para cada entrevistado tivemos uma duração média de duas horas de gravação em áudio, fazendo uso também de caderno de anotações. Mesmo os Estudantes com deficiência auditiva, participantes da pesquisa, conseguiam se expressar pela linguagem oral, sendo necessário, em alguns momentos, intervenção por parte da entrevistadora para esclarecimento de algumas falas.

Entre os Acadêmicos investigados, dois apresentavam deficiência auditiva e três deficiência física. Um dos entrevistados com deficiência auditiva possuía grande perda auditiva e fazia uso de aparelho auditivo, enquanto o segundo Estudante com a mesma deficiência apresentava pouca limitação auditiva, sem utilizar aparelho. Das três Discentes com deficiência física, uma apresentava tetrapesia, ou seja, perda parcial da motricidade nos quarto membros; outra Estudante apresentava limitações severas nos movimentos de rotação e elevação do braço esquerdo, com o qual não realizava atividades básicas, tendo em vista que $90 \%$ (noventa por cento) de seu movimento e força física estavam perdidos; a terceira Acadêmica, com distrofia dos membros musculares da cintura, tinha comprometimento no movimento dos membros inferiores e reduzida estatura.

O recorte da pesquisa envolveu participantes de diferentes cursos, sendo eles: arquitetura, odontologia, medicina, ciências contábeis e engenharia da computação. Essa seleção restrita foi necessária uma vez que nossa pesquisa foi de cunho qualitativo, portanto, não buscava analisar grande número de entrevistados, mas observar a diversidade de olhares sobre um mesmo tema. Portanto, entendemos a necessidade de ouvir Acadêmicos de cursos distintos (estudantes do curso de engenharia, porexemplo, raramente encontramos mesmosespaçosque os estudantes demedicina),

${ }^{3}$ Dados colhidos na prefeitura do campus em Belém junto à equipe de projetistas da universidade em janeiro de 2014. 
tipos de deficiência (para compreender o espaço sob diversos pontos de vista, observando, inclusive, se o espaço permanece acessível ou não a todos) e ingressantes em diferentes anos (para avaliar as mudanças/reformas ocorridas no período).

Por se configurar um estudo de caso, os dados foram coletados em diferentes momentos e com uma variedade de tipos de informantes (LÜDKE; ANDRÉ, 2012). Dessa forma, essa pesquisa pretendia a intercessão entre as informações teóricas e práticas, num complexo movimento de idas e vindas. Portanto, este artigo abrange pontos conflitantes acerca de uma mesma questão, emergindo da divergência de informações necessárias por meio de diferentes entrevistados.

Entre a entrevista padronizada ou estruturada, na qual o entrevistador tem que seguir muito de perto um roteiro de perguntas feitas a todos os entrevistados de maneira idêntica, e a entrevista aberta, que permite intervenções e adaptações a qualquer tempo, escolhemos a entrevista semiestruturada, a qual apresenta-se com um esquema básico permitindo ao entrevistador que faça possíveis adaptações (LÜDKE; ANDRÉ, 2012).

Para a coleta de dados, a entrevista pareceu-nos coerente na pesquisa uma vez que "permite a captação imediata e corrente da informação desejada, praticamente com qualquer tipo de informante e sobre os mais variados tópicos" (LÜDKE; ANDRÉ, 2012, p. 34).

Lüdke e André (2012, p. 35) citam que "o entrevistador tem que desenvolver uma grande capacidade de ouvir atentamente e de estimular o fluxo natural de informações por parte do entrevistado". Elegemos como instrumento para registro de dados a gravação, em virtude da possibilidade de registro da riqueza de expressões orais e pausas, presentes nas falas dos entrevistados, e tão importantes para compreensão das informações prestadas. Dessa forma também foi possível observar melhor a Pessoa entrevistada, dando-Ihe toda a atenção durante as gravações, além dos registros em caderno de anotação.

Procuramos por em dúvida conceitos que aparentemente estão solidificados e decidimos esmiuçar ideias, percepções e valores nas falas dos participantes. Para a organização e análise de dados, utilizamos a análise de conteúdo. Na elaboração das categorias, Franco (2005, p. 59) expõe dois caminhos que podem ser tomados: o de categorias predeterminadas em função de uma resposta específica do observador- categoria a priori; ou o caminho das categorias que "emergem da 'fala', do discurso, do conteúdo das respostas". Dessa forma "As categorias vão sendo criadas, à medida que surgem nas respostas, para depois serem interpretadas à luz das teorias explicativas" (FRANCO, 2005, p. 60).

Portanto, a análise de dados foi realizada com categorias de conteúdo criadas com base nas inferências produzidas a partir falas dos Entrevistados. Partimos das respostas dos entrevistados para a elaboração de categorias, analisando-as juntamente ao referencial teórico-metodológico.

Para este artigo nos detivemos na análise das entrevistas realizadas com os estudantes. Para tanto, buscamos identificar o que caracterizaria um espaço com acessibilidade física, sob a ótica desses estudantes, compreendendo as implicações das atuais condições de acessibilidade física da universidade em sua vida acadêmica, verificando quais obras na infraestrutura deveriam ser (ou têm sido) realizadas para garantir o ingresso e permanência de estudantes com deficiência na UFPA.

\section{3 | COM A PALAVRA, OS ACADÊMICOS: DISCUSSÃO E ANÁLISE DAS ENTREVISTAS}

Sabemos que o conceito da deficiência foi se delineando historicamente, tomando relevância política. Desse modo, a autoridade biomédica se viu contestada pelo modelo social da deficiência, o qual compreende a deficiência enquanto experiência do corpo com impedimentos associado a um ambiente com barreiras à participação desse sujeito na sociedade. Isso significa que o corpo 
com limitação pode não sofrer a opressão, dependendo da estrutura social concebida por meio da cultura da normalidade e das barreiras sociais encontradas.

O nó górdio do deslocamento do modelo médico para o social foi o silenciamento do corpo com limitação, o hiato entre a deficiência, como essencialmente medicalizada, para a deficiência sem um corpo, sem dor, sem fragilidades.

Neste artigo, o corpo com limitações não é esquecido. Partimos da ideia de que a Pessoa com deficiência apresenta impedimentos diferenciados, entretanto, é justamente na percepção das diferenças, e não no silenciamento destas, que balizamos a necessidade de ambientes não-uniformes, com modelos não estandardizados de arquitetura.

Uma questão essencial da nossa pesquisa buscou compreender a própria percepção dos estudantes sobre acessibilidade física. Para alguns entrevistados a acessibilidade física é a promoção de espaços para Pessoas com deficiência, conforme observamos no discurso de $D$ e $E$ :

Quando eu penso em acessibilidade física, na hora, eu penso na deficiência física da pessoa. Se exigem de um espaço acessibilidade, eu penso logo na deficiência física. Eu acho que ficou uma coisa estereotipada, talvez, por causa de esclarecimento. Penso em rampa, elevadores, esses tipos de aparato que amparem pessoas com deficiência física, limitações físicas. (D)

Um lugar acessível, para uma pessoa com deficiência auditiva como eu, seria um lugar tranquilo que me possibilita comunicar com as pessoas, sem que haja barreiras, como por exemplo, ambientes extremamente barulhentos, com obras ao lado, como acontece na UFPA, em muitos casos. Também com interferência de outras pessoas ao redor que não estejam se comunicando comigo, que fazem com que dificulte a minha comunicação com outras pessoas, porque eu não escuto o que as pessoas que estão falando comigo querem dizer, eu escuto vários barulhos e dificulta. Não é que seja um local ideal, mas um local que não apresenta barreiras. (E)

Permitam-nos uma observação breve, porém essencial para o entendimento das falas citadas acima. A Pessoa entrevistada, denominada aqui $D$, possui deficiência auditiva, do mesmo modo que $\mathrm{E}$. Entretanto, D não possui qualquer recurso que evidencie sua deficiência. Sua perda auditiva Ihe possibilita uma comunicação razoável a ponto de termos que interrogá-lo acerca de qual seria sua deficiência. Já o entrevistado $E$ utiliza aparelho auditivo e nosso diálogo demandava muitas pausas e boa dicção da entrevistadora.

Acerca desses dois casos de Pessoas com deficiência, lembramos a diferenciação que nos faz Goffman (1988) acerca dos desacreditados e desacreditáveis.

Para Goffman (1988), uma pessoa é desacreditada quando seu defeito é aparente, é percebido logo no contato visual, ao passo que a pessoa é desacreditável quando a diferença não está imediatamente aparente, não se tem dela um conhecimento prévio ou a pessoa não sabe que os outros a conhecem. Nesse caso:

Devido às grandes gratificações trazidas pelo fato de ser normal, quase todos os que estão numa posição em que o encobrimento é necessário, tentarão fazê-lo em alguma ocasião. Mais ainda, o estigma do indivíduo pode estar relacionado a questões que não convém divulgar a estranhos. (GOFFMAN, 1988, p. 66).

Portanto, observamos em D o desacreditável, o que garante o benefício da dúvida e do não pertencimento à categoria de Pessoas com deficiência, ainda que provisoriamente. Para E, a situação é do desacreditado, pois sua limitação e uso do aparelho auditivo não Ihe permite o "encobrimento" da deficiência.

Tal distinção fica clara no depoimento dos estudantes. Enquanto E coloca-se na posição da Pessoa com deficiência "Um lugar acessível, para uma pessoa com deficiência auditiva como eu...". Além de se inserir no rol das deficiências, o discente percebe a acessibilidade física a partir 
de suas necessidades auditivas, o que nos leva a crer que acessibilidade física não é um conceito universal, estanque, mas abordado a partir da experiência trazida pela deficiência do sujeito. $\mathrm{O}$ estudante apresenta deficiência auditiva, o que lhe impõe o olhar da acessibilidade a partir do ambiente livre de barreiras comunicacionais e não físicas.

Para D, a acessibilidade diz respeito às Pessoas com deficiência física o que não lhe insere no grupo-alvo. Esse acesso representa construções específicas para essas pessoas, estereotipadas, mas que não se apresentam semelhantes ao estudante entrevistado, ainda que ele seja também deficiente.

O fato da acessibilidade física demarcar o território da Pessoa com deficiência remete-nos à ideia de que "Os ambientes sociais estabelecem as categorias de pessoas que têm probabilidade de serem neles encontradas" (GOFFMAN, 1988, p. 5). O espaço que informa, também desenha o perfil dos que nele transitam, estabelecendo fronteiras e pilares de segregação social, mas também física.

A ideia da acessibilidade física também vem conjugada à espaços sem barreiras físicas, tanto para Pessoas com deficiência quanto sem deficiência. Essa constatação é vista na fala dos demais entrevistados.

Acessibilidade é um lugar onde todos possam frequentar, sem constrangimento, sem aproveitar daquele jeitinho brasileiro 'vem cá, me dá licença, me ajuda aqui!' (B)

É a facilidade de deslocamento para todas as pessoas. É terreno plano, sem muitos sobes e desces, sem rampas muito íngremes. É isso. (A)

Eu acho que é quando um portador de deficiência tem o direito de livre acesso, de ir e vir, e ter acesso a todos os lugares que as pessoas que não possuem nenhum tipo de deficiência têm acesso. Acho que o que torna um lugar acessível é a estrutura física do local que permite com que a gente que tem um pouco de dificuldade de acesso possa frequentar e usufruir os mesmos direitos que as pessoas não deficientes têm. (C)

O pensamento aqui volta- se ao coletivo humano, cheio de necessidades específicas, desiguais, de direitos de dessemelhança. Essa igualdade de direitos por meio do acesso físico torna-se essencial à medida que compreendamos a efemeridade da nossa condição de "normais", sabendo que: "Todos nós, de algum modo e segundo nossas próprias capacidades funcionais ou mentais, deparamo-nos com barreiras relacionadas ao movimento, às comunicações e ao alcance de compreensão de mensagens, instruções ou instrumentos" (DUARTE; COHEN, 2007, p. 155).

Em relação às sensações de prazer nos espaços físicos da UFPA, perscrutamos que locais eram convidativos aos estudantes com deficiência na universidade e por que esses ambientes traziam essa sensação a eles. Alguns entrevistados relacionaram o prazer à facilidade de acesso, contato com as pessoas ou ligados ao contato com a natureza.

Eu gosto muito da Biblioteca Central (BC). Eu gosto do acervo de livros, do ambiente, das pessoas que atendem a gente. Eu gosto também do fato de para termos acesso a ela terem rampas e possibilitar que nós tenhamos acesso a toda a infraestrutura do local. (C)

Prazer? No caso, são as áreas mais ecológicas, a parte das árvores. Porque o terreno é mais plano, é um ambiente mais natural. É o que eu gosto. (A)

O prazer está ligado ao descanso e vem ao encontro do que deveria ser a cidade universitária, comunidades com muito verde, um rio ou lago, sempre remetendo à natureza, à espacialidade bucólica (PINTO; BUFFA, 2009).

Para nós, essa motivação para o contato com a natureza na fala de $A$, representa também uma tentativa de isolamento. Mesmo sendo locais abertos ao público, o olhar não está voltado especificamente a alguém. Entendemos que o local prazeroso para os estudantes entrevistados é aquele em que não são observados, não são postos à avaliação de outras pessoas. 
Sorveteria, que é um ambiente que eu posso me comunicar com meus amigos e, ao mesmo tempo, descansar, entre as minhas atividades. E os lugares que a gente tem um pouco de contato com a natureza, que seriam as árvores que ficam próximo do rio, mas não necessariamente o rio em si, mas um lugar agradável. Porque relaxa, principalmente, a minha mente. (E)

$A B C$, eu acho interessante, não acho acessível. É calmo, um lugar onde todo mundo ali está com um propósito, sem te olhar, sem querer saber de fato. Eu não gosto muito desse olhar de crítica. Às vezes eu passo e a pessoa olha meu braço e a cicatriz e... já tiveram até absurdos, um homem no posto de gasolina que meteu o dedo assim e passou... [ela faz o gesto no braço] e ele disse 'é grande, né?' Sabe? Absurdo! A pessoa olha a cicatriz... sabe aquela sensação de dor quando tu vês alguém que se machucou? Eu sinto muito isso na cara das pessoas. E o primeiro contato quando eu estou assim, de blusa de alcinha, a pessoa não me olha... ela fica olhando para a cicatriz, até eu falar o que foi, até ela matar a curiosidade dela. Acho que provoca muito a curiosidade. (B)

Chamou-nos atenção o episódio narrado por $\mathrm{B}$, a respeito da fixação de uma pessoa sobre sua cicatriz. Segundo Goffman (1988, p. 7), o estigma que envolve as abominações do corpo - deformidades físicas - possui como característica sociológica marcante o fato de que: "um indivíduo que poderia ter sido facilmente recebido na relação social quotidiana possui um traço que podese impor a atenção e afastar aqueles que ele encontra, destruindo a possibilidade de atenção para outros atributos seus."

Portanto, o corpo cicatrizado imprime em si as marcas de uma segregação que pode ser à primeira vista ou velada. Inferimos que B teme uma exposição, portanto, opta por espaços neutros, conforme notamos nessa fala

As pessoas com estigma corporal buscam a convivência com as demais pessoas com as quais têm uma relação cotidiana, pois creem que estas não colocarão em evidência sua incapacidade. A cisão entre mundo do indivíduo em lugares públicos versus lugares retirados, revela a separação entre a deficiência exposta e aquela que se pode ocultar (GOFFMAN, 1988).

Ainda na fala de $\mathrm{B}$, observamos a sensação do prazer do espaço universitário como local privilegiado.

Eu acho a universidade muito bonita! Ficar ali na beira do rio, dá para viajar de várias formas, quem sabe? E aí eu fico assim, às vezes, me questionando muito sobre o que tem do outro lado do rio. Tem tanta gente ali do outro lado do rio que não vem para cá. Não vem para cá, não porque quer, é porque nunca vai ter a possibilidade, sabe?! E aí, quando eu olho aqui ao meu redor, que eu vejo que tem gente aqui do Guamá, gente passando para caminhar, eu fico 'cara, olha só!' Eles devem estar olhando para a gente assim 'olha, eu queria estar aí e eu não estou'. É um privilégio! (B)

Ao relacionar estudos entre educação superior e organização do espaço universitário, Pinto e Buffa (2009) fazem uma avaliação crítica acerca da inadequação de edifícios para fins universitários, os quais renegam, muitas vezes, as diversas formas de sociabilidade dos espaços e a dinâmica dos processos pedagógicos existentes no ensino superior. Afirmam ainda que espaços universitários reproduzem, muitas vezes, formas de acumulação capitalista, locais marcados pela violência contra trabalhadores, moradores locais e também contra a natureza.

A UFPA fica situada no bairro mais populoso da capital, com moradores, predominantemente, de baixa renda. É comum observar a presença da comunidade no campus, seja realizando a caminhada matinal ou valendo-se dos serviços gratuitos oferecidos. O campus mantém uma relação imediata com a estrutura urbana, ora interagindo com o bairro, ora isolando-se dele. Nesse grupo de vulnerabilidade, encontramos os moradores do entorno do campus, mas também os próprios estudantes com deficiência. 
A sensação de território privilegiado, do campus como espaço de conquista e vitória de $B$, faz-nos perceber que a linha imaginária que separa desafortunados e vencedores também é desenhada pelos muros da universidade. O espaço mais uma vez marca o lugar das pessoas, de (não) pertencimento.

Em relação às implicações das barreiras físicas na vida acadêmica, desejávamos conhecer de que maneira a dificuldade de deslocamento poderia ter (ou não) impedido/dificultado a participação dos estudantes com deficiência em atividades acadêmicas.

Para A, houve momentos de dificuldade no campus de Belém que impediram sua participação como estudante.

Já, já aconteceu. Porque, como eu faço arquitetura, tinha uma matéria que a gente tinha que sair para observar a paisagem, várias coisas a gente tinha que observar. E nisso, a turma tinha que andar muito para vários lugares da federal. E eu, como tomei conhecimento de que a gente tinha que andar muito, não participei dessa aula. Foi bem chato, assim... porque era uma aula prática e eu precisava daquilo e eu não fui porque tinha que andar muito e, tanto os alunos, como dizem, normais, reclamaram que tiveram que andar muito, imagina eu?! (A)

Buscamos observar o olhar desses estudantes em movimento, no deslocamento de um ponto a outro. A questão do acesso é dificultada quando A relata a necessidade de explorar o espaço da universidade, saindo um pouco de sua rota convencional. Nesse momento o ambiente torna-se obstáculo, pela amplitude do local. Sobre atividades que extrapolem o ambiente das salas de aula, os autores escrevem:

Como sabemos, a atividade de ensino pode ocorrer em qualquer lugar. Os exemplos são muitos. Entretanto, num campus universitário, a ausência de espaços apropriados dificulta a realização de atividades extracurriculares, como artísticas e de extensão, que geralmente dão personalidade à população acadêmica e são importantíssimas para a formação do cidadão. (PINTO; BUFFA, 2009, p. 141).

Para E e B, não houve barreiras na realização de atividades acadêmicas, como concluímos nas falas abaixo.

Dentro da UFPA em si, não. Primeiro, porque no meu curso basicamente é totalmente centrado no campus profissional. Então, nós não temos interação com outros campi. Então, o deslocamento, dentro da UFPA, é muito tranquilo para mim. Basicamente, eu só preciso me locomover a pé, no instituto, para realizar minhas atividades. (E)

Não. Por conta de que a minha própria deficiência não se enquadra. Para mim ela não me dificultou, nesse aspecto. Como eu te falei, a única dificuldade que eu acho que a minha deficiência realça assim, que ela vai gritar, é quando eu vou tentar subir nesse ônibus, que eu odeio esse circular! (risos) Eu odeio, eu só subo pela frente [...] Eu entro e vou falando 'espera aí que eu só me seguro com um, o outro é só enfeite'. Eu tenho que me identificar. (B)

$\mathrm{O}$ fato de não ter sido mencionada alguma dificuldade para acesso às atividades esportivas, culturais, seminários, também demonstram, como na fala de $\mathrm{E}$, que o estudante não compreende essas atividades como parte da vida acadêmica. As atividades citadas envolvem apenas as salas de aula e laboratórios, localizadas no mesmo instituto.

Para B, o impedimento não acontece porque sua deficiência não representa dificuldade de locomoção. Entretanto, ao tentar acessar o ônibus circular, que lhe permite o deslocamento para alcance de atividades em pontos distantes dentro do campus, B informa o desconforto para tal ação.

De alguma forma, o acesso de B é possível mediante a exposição de sua deficiência. Acerca desse fato, Goffman (1988, p. 87) explica que a pessoa: 
pode voluntariamente revelar-se, transformando, portanto, radicalmente a situação de um indivíduo que tem informações a manipular na de alguém que deve manipular situações sociais difíceis, transformando a situação de uma pessoa desacreditável na de uma pessoa desacreditada. Uma vez que a pessoa que tem um estigma secreto dá informações sobre si, pode-se entregar a qualquer uma das ações, anteriormente citadas, ao alcance de estigmatizados conhecidos como tais, podendo isso explicar, em parte, a sua política de auto-revelação. Um dos métodos de revelação é o uso voluntário, por um indivíduo, de um símbolo de estigma, um signo extremamente visível que revela o seu defeito onde quer que ele vá.

A revelação de seu "defeito" é a porta de entrada para garantir seu direito de acesso ao ônibus de modo não convencional, ou seja, pela porta da frente. A Pessoa passa a manipular situações de desvantagem que precisam ser utilizadas para seu benefício no cotidiano.

Segundo D e C, apesar das barreiras físicas, é no esforço pessoal que se garante a participação em atividades acadêmicas.

Eu tenho uma experiência que, há mais ou menos 3 meses atrás, 3 a 2 meses, ocorreu uma palestra que tinha duração de 3 dias, mais ou menos. Essa palestra era no hangarzinho ${ }^{4}$, que fica lá pro outro lado também. Essa distância dificultou mas não me fez desistir de chegar no local por conta do peso da palestra que ia garantir a carga horária, essas coisas que a gente tem que acumular durante o período acadêmico, um determinado número de horas, em palestras, mini-cursos. Então a maior pressão foi em conseguir essas horas. (D)

Ah, não. Porque eu tento não olhar para dificuldade, eu tento superar. Então, mesmo quando eu tenho provas, algumas provas são feitas no segundo andar, então eu acabo subindo as escadas mesmo que me canse e que me traga algumas dores, às vezes (risos), eu faço sempre esse esforço, eu tento sempre não fazer com que essas pequenas dificuldades me atrapalhem de obter o conhecimento que eu preciso no curso.

(Pergunto onde encontra essa força para superar os obstáculos)

Acho que a vontade de continuar estudando e adquirir conhecimento para poder exercer a profissão. (C)

Para a Classificação Internacional de Funcionalidade, Deficiência e Saúde (CIF), movimento que contou com a participação de Pessoas com deficiência e diversos movimentos sociais, barreiras são "os fatores ambientais cuja presença ou ausência limitam o funcionamento de um indivíduo e criam a deficiência" (DINIZ, 2012, p. 47).

Nesta senda, a CIF caracteriza a deficiencia:

pelo resultado de um relacionamento complexo entre as condições de saúde de um indivíduo e os fatores pessoais e externos. É um conceito guarda-chuva para lesões, limitações de atividades ou restrições de participação. Denota os aspectos negativos da interação entre o indivíduo e os fatores contextuais. (DINIZ, 2012, p. 48).

Na inclusão da Pessoa com deficiência no ensino superior, vemos ainda a dificuldade de participação dessas Pessoas nas atividades que constituem o currículo do curso universitário. $\mathrm{Na}$ fala de C, fica clara a separação entre o deficiente e a barreira física. Na entrevista, C parece compreender que não consegue alcançar as tarefas propostas devido sua deficiência e não na relação entre ambientes inacessíveis e corpo com deficiência.

${ }^{4} \mathrm{O}$ Centro de Convenções Benedito Nunes da UFPA é chamado pelos estudantes de hangarzinho, fazendo alusão à uma obra conhecida em Belém pela beleza e imponência, o Centro de Convenções da Amazônia - Hangar. 
Algumas aulas que tiveram que adaptar, mudar alguns instrumentos, mudar até mesmo a condução da aula, dos assuntos e tiveram algumas aulas que nós não pudemos ver que a turma " $X$ ", no caso, que também iniciou agora, no mesmo semestre que a gente, eles fizeram essas aulas e nós não pudemos ter. Eu me sinto um pouco triste porque eu sinto que eu estou prejudicando os demais alunos da minha turma. (C)

A culpa sobre a Pessoa com limitações prevalece no discurso de C. Sua inclusão acaba excluindo os demais estudantes de atividades essenciais do currículo do curso. A história proferida acima demonstra o desconforto que sua presença trouxe à turma, a situação desfavorável que a estudante trouxe à turma.

O ensino superior no Brasil teve início no século XIX, com cursos isolados. Na primeira metade do século $X X$, os cursos oferecidos nas universidades formavam os quadros profissionais para 0 Estado: cursos militares, medicina, química, economia política e produtores de bens simbólicos: música, desenho, história e arquitetura. A formação nas universidades pretendia o preparo das elites do país (PINTO; BUFFA, 2009).

Os edifícios da UFPA datam da década de 1960. Nesse momento histórico, o ingresso de estudantes com deficiência no ensino superior não era fato possível. Portanto, grande parte das edificações do campus não é apropriada ao acesso de Pessoas com impedimentos, porque não foram pensadas contando com a presença delas, observando as possibilidades de uso de Pessoas com deficiência nos espaços da instituição.

Da mesma forma, ainda hoje é possível verificar a dificuldade de $\mathrm{C}$ no uso de um dos blocos de aula. Não pretendemos ignorar a existência da deficiência em si, enquanto um fenômeno biológico, mas evidenciamos a deficiência que passa a representar uma situação de desfavorecimento, de exclusão, a partir da estrutura física inadequada. A ênfase está sobre a deficiência que determina a não participação dos sujeitos nas atividades universitárias.

Concordamos com a atitude de $\mathrm{C}$ diante dos obstáculos enfrentados, sua atitude aguerrida perante os percalços da graduação. Todavia, sua fala demonstra que houve situações em que seu esforço pessoal não foi suficiente para garantir o acesso aos mesmos laboratórios e salas que os demais estudantes, que não deu conta do problema da exclusão, via construções não acessíveis.

Ao avaliar a organização do espaço da sala de aula, os estudantes citaram aspectos relevantes quanto à estrutura do campus:

Tem professor que gosta de deixar em semi- lua, para poder interagir; tem professor que gosta daquele estilo clássico 'sou professor e vocês são alunos, fiquem aí atrás'. Mas eu não tenho muita preocupação com isso, não me atrapalha. (B)

A UFPA, vai passando algum tempo, eles vão aumentando o número de vagas, mas eles não aumentam as salas, entendeu? Então a sala da minha mãe comportava 20 alunos, há 10 anos atrás. Hoje, a mesma sala comporta 40 alunos. Aí fica um pouco complicado, porque o espaço vai diminuindo, vai prejudicando o conforto, porque é muita gente apertado e isso prejudica sim no desempenho. (D)

Ao traçar um breve histórico do crescimento das universidades, Pinto e Buffa (2009, p. 26-27) escrevem:

O número dessas salas de ensino ou universitas aumentou proporcionalmente ao crescimento das cidades [...]. Consequentemente aumentava o número de estudantes, novos consumidores, que eram bem-vindos e recebiam tratamento especial de toda a comunidade, o que não era inusitado, pois mesmo alguns pobres eram financiados por nobres ou pela Igreja e sempre tinham algumas valiosas moedas para gastar e garantir a prosperidade do comércio e da cidade. 
Ao longo da história, a universidade cresce com o desenvolvimento das cidades. No que concerne ao ensino superior, assistimos à transformação de seu modelo: do ensino meritocrático, destinado à formação das elites, passa-se a um modelo assistencialista. Isso demonstra o porquê da escassez de investimentos nas IES públicas, sobretudo na infraestrutura.

Mesmo com as novas tecnologias, estudiosos da educação e arquitetura afirmam que "as salas de aula ainda são construídas apenas com previsão de espaço para carteiras, mesa, lousa e, quando muito, duas tomadas elétricas, janelas sem cortinas e ventilação precária" (PINTO; BUFFA, 2009, p. 144).

A disposição do mobiliário da sala e a localização do professor evidenciam a multiplicidade de práticas pedagógicas na UFPA. Ora dispostos em fileira, ora em duplas ou semi-círculo, o espaço informa ao estudante onde cada sujeito participante do ensino encontra-se, como relatou-nos B "tem professor que gosta daquele estilo clássico 'sou professor e vocês são alunos, fiquem aí atrás'”.

A respeito do espaço escolar, estamos de acordo que: "Os espaços educativos, assim como os lugares que admitem a leitura acadêmica, estão dotados de significados e transmitem uma quantidade importantedeestímulos, conteúdoseavaliaçõesdochamadocurrículooculto"(BENITO,2000, p. 184).

A estrutura física da UFPA tem passado por diversas mudanças, tanto na construção de novas obras quanto na reforma das existentes. Desejávamos saber quais foram os benefícios de construções e reformas no campus na vida do estudante.

Aquela reforma que fizeram nas entradas, logo quando a gente entra na universidade, no portão 3, que foram fazendo aqueles caminhos. Porque antes, o terreno era irregular. Eles construíram aquela calçada que ficou mais plano. Isso parece que é pouco, mas é muito para quem tem que se deslocar. (A)

Recentemente, a faculdade começou a cobrir todos os corredores e isso é muito interessante porque chove muito, ou, quando não chove muito, está muito quente. Eles fizeram toda cobertura posterior da ponte e está muito mais seguro. (E)

Eu acho as rampas que existem por toda a federal, que tem muitas rampas mesmo! A gente tem acesso ao ver-o-pesinho ${ }^{5}$, ao $R U$ (do Básico), à $B C$, aos bancos que ficam próximos da reitoria. Então, eu acho que as rampas ajudam muito a gente na acessibilidade dos locais. (C)

A ampliação de passarelas e rampas foi citada pelos estudantes como grande benefício por conta das questões climáticas e de locomoção. O espaço físico, que geralmente privilegia o deslocamento de automóveis, passou a significar para os estudantes com deficiência que não possuem automóvel próprio um ambiente voltado também ao transeunte.

A construção de lanchonetes e do RU, no setor profissional, são lembradas por estudantes como essenciais na UFPA. Os comentários dos entrevistados nos fazem crer que mudanças na estrutura física da universidade são necessárias e bem-vindas, independentemente da limitação dos que circulam no campus. A esse respeito, Benito (2000, p. 191, tradução nossa) escreve que: "A arquitetura escolar é um elemento cultural e pedagógico não somente pelos condicionamentos que conduzem suas estruturas, mas também pelo papel de simbolização desempenhado pela vida social."

Em seus 57 anos de existência, a UFPA contou e conta com diversas obras de restauração e adaptação de prédios, novas edificações e vias de acesso no interior da instituição (UNIVERSIDADE FEDERAL DO PARÁ, 2014). Somente a partir do ano de 2009 as obras de acessibilidade física foram implementadas no campus da UFPA em Belém. Entre as principais ações voltadas à implementação da acessibilidade física no campus foram-nos apontadas: construção de passarelas,

\footnotetext{
${ }^{5}$ Ver-o-pesinho é o nome dado pelos estudantes ao conjunto de lanchonetes próximas aos blocos de salas de aula. Esse nome faz alusão ao Mercado Ver-o-Peso, o qual abastece a cidade com frutas, verduras e outros alimentos regionais.
} 
rampas e instalação de plataformas e elevadores ${ }^{6}$. Mesmo diante de recursos escassos e demandas diversas, a prefeitura tem buscado desenvolver projetos que viabilizem o acesso de Pessoas com deficiência na UFPA. Esse empenho tem esbarrado, muitas vezes, na falta de recursos financeiros para continuidade de execução das obras.

A prefeitura desenvolveu uma proposta de sinalização para todo o campus no ano de 2013. Todavia, o projeto não pôde ser concretizado por falta de verbas, o que ocasionou em sua modificação para atender apenas ao setor básico da UFPA, a qual também aguardava liberação do orçamentário (UNIVERSIDADE FEDERAL DO PARÁ, 2014)

Portanto, observamos que as reformas e construções da universidade esbarram em um cenário político-econômico de destinação de verbas e continuidade de projetos iniciados em diferentes momentos históricos. Nesse sentido, entendemos que o espaço físico tem sido priorizado segundo orçamento e visão política de cada gestão universitária.

Acerca de construções e reformas, Sassaki (2010) lembra-nos que a acessibilidade física, no sentido de eliminação de barreiras em ambientes físicos, passou de uma perspectiva da Pessoa com deficiência para usufruto de todas as pessoas, sejam elas deficientes ou não. Portanto, há que se observar que as obras realizadas no campus devem seguir a premissa da garantia de mobilidade a todos os que freqüentam esse espaço.

A experiência do primeiro dia de aula dos estudantes na UFPA foi narrada de modo que pudemos conhecer o primeiro contato dos estudantes com deficiência com a UFPA:

Foi complicado pela distância, porque eu não estava acostumada, né? Eu não entendia que seria assim, eu estava naquela ilusão 'Ah! Se for distante eu pego o ônibus'. (A)

Foi muito assim, foi muito estressante o primeiro dia porque a gente não sabia onde ia ser a primeira aula. Acho que a federal pecou um pouco nesse quesito, de informar melhor para os alunos a programação das aulas e o local de cada aula. (C)

Nos discursos de A e $\mathrm{C}$, as expressões "complicado" e "estressante" marcam o primeiro dia de aula na UFPA. A estrutura física com ausência de sinalização e falta de informação no campus parece desorientar o calouro. Os relatos de D e E demonstram uma experiência bem diferente, um primeiro contato positivo com a universidade.

Eu lembro que no primeiro dia de aula a gente fez uma visita rápida aqui na UFPA. A gente olhou as salas, não ficou nas salas de aula, levaram a gente para o Instituto de Ciências Sociais e Aplicadas (ICSA), que é o instituto que abriga o curso de contabilidade e mais 6 cursos. Lá a gente teve algumas palestras sobre o curso, a parte profissional, a parte científica. Inclusive, é um ponto legal, que me chamou muito atenção. A estrutura do Instituto realmente me chamou muita atenção, porque o instituto está todo reformado, tem laboratório, tem as cadeiras boas, então a estrutura chamou atenção naquele dia. (D)

Foi muito excitante, na verdade! Porque quando a gente sai do ensino médio, para mim, era a primeira vez aqui na UFPA! E entrar numa faculdade tendo 17 anos e sendo deficiente auditivo, a gente não sabe o que espera. São pessoas completamente novas, são professores diferentes e foi uma experiência incrivel porque quando a gente entra... a gente entra na UFPA e vai caminhando pra sala de aula, a gente se sente bem. Porque a gente sabe que as pessoas ao redor da gente, que estão caminhando juntas, que passam, são pessoas que se dedicaram, são pessoas que estão aqui por um motivo. (E)

O campus universitário representa para $\mathrm{D}$ e E, um espaço de imponência, de primazia de estudos superiores. Nas palavras de E, a UFPA apresenta-se como um gueto de pessoas com um

${ }^{6}$ Dados concedidos pelo Departamento de Estrutura Física (DIESF) da Prefeitura da UFPA em 2014. 
mesmo objetivo. Percebemos então que os muros da instituição delimitam não apenas o território espacial das pessoas, mas demarcam vidas, projetos e realidades.

Sinalizamos que o uso das estruturas imponentes do ensino superior representa para $\mathrm{E}$ um novo ciclo que se inicia, no qual, ele, com deficiência auditiva, não sabe o que esperar, não conhece quem são seus novos pares. Sobre essa expectativa, gerada pela incerteza, Goffman (1988, p. 15) desperta-nos para o fato de que:

\footnotetext{
O cego, o doente, o surdo, o aleijado nunca podem estar seguros sobre qual será a atitude de um novo conhecido, se ele será receptivo ou não, até que se estabeleça o contato. Essa incerteza é ocasionada não só porque o indivíduo não sabe em qual das várias categorias ele será colocado mas também, quando a colocação é favorável, pelo fato de que, intimamente, os outros possam defini-lo em termos de seu estigma.
}

Ao mesmo tempo em que o estudante goza de símbolos de prestígio, por cursar o ensino superior na universidade que tem o processo seletivo de maior concorrência no estado do Pará, também sofre a incerteza trazida pelos símbolos de estigma, pelo fato de ter deficiência auditiva.

Esses estudantes têm muito a dizer... e disseram! Às vezes, em uníssono, às vezes em sólo. Queríamos ouvir sugestões à estrutura física para circulação de estudantes com deficiência na instituição. Nesse momento, os estudantes puderam propor recomendações, ainda que ignorando os termos técnicos da arquitetura, mas a partir dos seus pontos de vista como usuários que vivenciam a UFPA em diversos espaços.

Olha, em primeiro, seria a questão das rampas. A questão dos blocos, eles têm sim um acesso bom, na entrada das salas, a largura das portas, dos ambientes em geral, também considero que tenha um bom acesso. Em todos os lugares da UFPA que eu já frequentei, não frequentei muitos, mas em todos, inclusive do meu bloco, não tem pias baixas. (A)

As sugestões apresentadas por A fazem-nos afirmar que as construções no campus e mobiliário necessitam de melhorias que levem em conta a existência das pessoas com deficiência. Os espaços são projetados para um público predeterminado, com medidas corporais padronizadas. Essas estruturas não alcançam as necessidades de algumas pessoas que estudam na instituição.

Eu acho que poderiam ter rampas em alguns outros locais. Acho que esses prédios precisam ser adaptados e poderiam ser instalados os elevadores, porque eles já compraram os elevadores, a federal já adquiriu eles e os prédios, alguns prédios, possuem a estrutura pra instalação dos elevadores, só que ainda não foi realizado esse trabalho. (C)

Analisando as falas, observamos que as sugestões caminham para uma continuidade nas obras realizadas. As rampas e elevadores, por exemplo, são citados como elementos essenciais à acessibilidade física dos estudantes, os quais não negam a existência desses recursos no campus. Entretanto, há uma necessidade de celeridade na instalação desses equipamentos e construção de novas rampas.

Para D, a inspiração para alternativas que facilitariam a acessibilidade de estudantes na UFPA estaria em estudos voltados ao tema.

Eu nunca visitei uma outra universidade além da UFPA. Então eu não posso fazer nenhum comparativo concreto. Mas eu acredito que nas outras universidades do mundo devem ter muitos exemplos que a própria universidade possa adquirir. Se houvesse um investimento em estudos em relação a isso, de pessoas que se comprometessem academicamente e na questão prática de instituir coisas que venham a promover essa inclusão, eu acho que seria um passo primordial para a universidade. (D)

Insistimos que é por meio da presença de Pessoas com deficiência que as estruturas da universidade se veem forçadas a novas construções e adaptações que universalizem sua estrutura física. 
Sem essa demanda real, concreta, incômoda, não haveria a urgência dessas medidas e o privilégio da convivência com Pessoas com deficiência no ensino superior. Conforme nos adverte Bachelard (1993, p. 25), "na mais interminável das dialéticas, o ser abrigado sensibiliza os limites de seu abrigo", sejam os abrigos físicos ou do pensamento socialmente construído que exclui determinados grupos de pessoas.

Esses espaços inacessíveis da universidade revelam o silenciamento dos corpos com impedimentos nas estruturas políticas da UFPA. Conforme nos explica Benito (2000, p. 201, tradução nossa) "A arquitetura escolar pode ser observada como um programa educador, ou seja, como um elemento do currículo oculto e silencioso, mesmo que ela seja por si só bem explícita ou apresentada."

Ao analisarmos a estrutura física do campus pudemos inferir que, explicitamente, não havia "lugar" para as Pessoas com deficiência. Contudo, sabemos que os estudantes que atualmente ali estão, aos poucos, contribuem para que esse cenário seja modificado.

Dizer que a UFPA não tem buscado pensar na acessibilidade física não seria coerente. Observamos pela fala dos estudantes com deficiência entrevistados que há espaços acessíveis na instituição e que muitos ainda necessitam de continuidade.

Estamos com Diniz (2012, p. 69) quando escreve que "Há desigualdades de poder que não serão resolvidas por ajustes arquitetônicos". Mas também acrescentamos que a eliminação de barreiras não traria a independência aos deficientes, mas garantiria a possibilidade de acesso aos mesmos direitos que as demais pessoas. O que concebemos aqui é a ideia de que o corpo vai além da fronteira física, reafirmando a pluralidade e diversidade como estilos de vida, o que demanda estruturas físicas plurais, pensadas a partir de um ser humano também diverso.

\section{4| CONIDERAÇÕES FINAIS}

Afirmamos que o espaço físico é planejado e materializado com intencionalidade, delineando em suas formas a presença/ausência de determinadas pessoas, constituindo a (in)visibilidade das Pessoas com deficiência nos ambientes, inclusive, educacionais.

Partindo dessa concepção, buscamos conhecer a ideia que os acadêmicos com deficiência faziam da acessibilidade física. Eles afirmaram a acessibilidade física como conceito que não pode ser universal, único e independente, mas construído na interação do sujeito com o espaço. Vimos que essa experiência varia segundo as características físicas do usuário, sejam elas de deficiência ou outras limitações. Para os discentes com deficiência, o ambiente acessível traz em seu bojo a ideia de acesso a todos, sobretudo aqueles com deficiência, porém, não destinados exclusivamente a eles.

Considerando a diversidade humana, as estruturas físicas precisam ser repensadas quanto à ideia de padronização dos espaços. Entendemos que ambientes inacessíveis contribuem para a experiência da exclusão. Nesse contexto, o ensino superior, enquanto espaço educativo e inclusivo, deve trabalhar na contramão desse processo segregador, promovendo acessibilidade física a todos quantos fizerem uso desse espaço.

Analisando as implicações das obras de acessibilidade física na vida acadêmica dos estudantes com deficiência, inferimos que as atuais construções/reformas promovidas no campus têm beneficiado a vida dos discentes. Os entrevistados compreendem que a universidade funciona como pólo atrativo de conhecimento, como centro de socialização de saberes que só é possível mediante sua estrutura física. Portanto, as obras que viabilizam o acesso dos discentes com deficiência na instituição proporcionam a presença desse estudante no campus e sua interação com os demais colegas, o que enriquece a construção da vida acadêmica. 
A reconstrução de modelos processuais dos cursos de vida, a que Weller se refere foi realizada pela análise de eixos resultantes das entrevistas narrativas, os quais sintetizamos no quadro 3 , após as etapas descritas nas páginas anteriores, com olhar voltado aos objetivos da pesquisa. $A$ interpretação esteve sustentada pelo referencial teórico adotado, o qual orientou a própria elaboração dos objetivos.

Os eixos são experiências de aprendizagens que, construídas ao longo da vida das professoras que participaram desta investigação, podem ser estendidas aos grupos sociais com os quais elas se identificam. Assim como em outras pesquisas com narrativas autobiográficas em educação, esta também se inscreve na lista daquelas que ampliam e produzem conhecimentos sobre a pessoa em formação, suas relações com territórios e tempos de aprendizagem e seus modos de ser, fazer e biografar resistências e pertencimentos. Pelas semelhanças também é possível construir uma história coletiva da profissão docente.

Os estudantes sugerem ainda a continuidade e expansão das obras de acessibilidade física. Esse dado chamou-nos atenção em virtude de que, mesmo diante das dificuldades evidenciadas pelos acadêmicos no uso do espaço universitário, há reconhecimento de avanços na infraestrutura da universidade. Precisamos desconstruir concepções equivocadas a respeito do espaço universitário!

O espaço, inegavelmente, não está estruturado por acaso. Ele informa, forma, identifica, favorece e desfavorece, organiza ou desorganiza o que lhe é significativo. A UFPA está inserida como esse tipo de espaço, que representa e influencia o aprendizado de seus estudantes, trazendo em sua estrutura física aspectos que influenciam no rendimento de seus discentes. O espaço da Universidade proporciona o aprendizado, como mediador, mas também como protagonista, como espaço que desenha seus contornos que delimitam pessoas, práticas e aprendizado.

Salientamos que os entrevistados indicaram como sugestão para melhoria do acesso ao campus o fomento a pesquisas voltadas ao tema da acessibilidade física, em busca de ações que levassem em conta a realidade dos acadêmicos e da UFPA. Concordamos com esse posicionamento porque, conforme nossa pesquisa demonstrou, o espaço não pode ser projetado sem levar em conta a diversidade das pessoas que o frequentam.

Sabemos que os projetos que deram vida à UFPA em sua criação não foram pensados para estudantes com deficiência, entretanto, essas estruturas necessitam ser modificadas a partir do momento em que Pessoas com deficiência se fazem presentes na UFPA. O reconhecimento de que a estrutura física engendra processos de motivação, respeito e valorização de Pessoas com deficiência no ensino superior deve impulsionar as ações de acessibilidade física na UFPA.

Portanto, ratificamos essa necessidade e evidenciamos como essencial o fomento à realização de outros estudos acerca da acessibilidade física, a partir do olhar da percepção de estudantes com outras deficiências, como a visual, intelectual, múltipla, com autismo e outros transtornos do desenvolvimento. Somente assim será possível pensar e projetar espaços que atendam às demandas de todas as pessoas, de uma estrutura física voltada à diversidade humana.

Sabemos que os projetos que deram vida à UFPA em sua criação não foram pensados para estudantes com deficiência, entretanto, essas estruturas necessitam ser modificadas a partir do momento em que Pessoas com deficiência se fazem presentes na UFPA. O reconhecimento de que a estrutura física engendra processos de motivação, respeito e valorização de Pessoas com deficiência no ensino superior deve impulsionar as ações de acessibilidade física na UFPA. 
ACESSIBILIDADE FÍSICA | Carolline Septimio, Genylton Odilon R. da Rocha e Geovana M. L. Mendes

\section{Referências}

BACHELARD, G. A poética do espaço. São Paulo: Martins Fontes, 1993.

BENITO, A. E. Tiempos y espacios para la escuela: ensayos históricos. Madri: Biblioteca Nueva, 2000.

DINIZ, D. O que é deficiência. São Paulo: Brasiliense, 2012.

DUARTE, C. R. de S.; COHEN, R. Turismo para todos: metodologia para confecção de uma guia do Brasil acessível. In: TUNES, E.; BARTHOLO, R. (Org.). Nos limites da ação: preconceito, inclusão e deficiência. São Carlos: EdUFSCar, 2007.

FRANCO, M. L. P. B. Análise de conteúdo. 2. ed. Brasília: Liber Livro Editora, 2005.
GOFFMAN, E. Estigma: notas sobre a manipulação da identidade deteriorada. 4. ed. Rio de Janeiro: LTC, 1988.

LÜDKE, M.; ANDRÉ, M. E. D. A. Pesquisa em educação: abordagens qualitativas. São Paulo: E.P.U, 2012.

PINTO, G. de A.; BUFFA, E. Arquitetura e educação: câmpus universitários brasileiros. São Carlos: EdUFScar, 2009.

SASSAKI, R. K. Inclusão: construindo uma sociedade para todos. 8. ed. Rio de Janeiro: WVA, 2010.

UNIVERSIDADE FEDERAL DO PARÁ. Prefeitura: UFPA em números. 2014. Disponível em: <http://www. ufpa.br>. Acesso em: 16 maio 2014. 